\title{
Identifying the effective factors on customer knowledge management development: Evidence from customs industry
}

\author{
Saeedeh Arazpoor* and Mohammad Mahmodi Meymand
}

\section{H R O N I C L E}

\section{Article history:}

Received August 28, 2015

Received in revised format

November 28, 2015

Accepted December 1, 2015

Available online

December 2, 2015

\section{Keywords:}

Knowledge management

Customer knowledge management

Customer knowledge development

Customs

\begin{abstract}
A B S T R A C T
This paper examines the effect of different factors on customer knowledge management development for a custom organization in Bandar Abbas, Iran. The statistical population of this research includes all 440 managers and employees in different levels where 205 people are randomly selected for this survey. Using t-student as well as Friedman tests, the study has confirmed that organizational culture, training, strategy, information and organizational infrastructure, top management commitment, organizational conflict, standardization, employee performance, communication, budget support and necessary skills could influence positively on knowledge management development. In our survey, training is also believed to be the most influential factor.
\end{abstract}

\section{Introduction}

Customer knowledge management, with integrating 2 concepts of knowledge management and customer relationship management, has effectively stepped in products development and services improvement which are presented to customers. Knowledge management seeks receiving, storing, utilizing and sharing knowledge within the organization. However, customer relationship management investigates customer relationship improvement and concepts such as loyalty. Customer knowledge management causing synergistic effect of knowledge management and customer relationship management integration will be able to recognize its customers' needs and predict those (Abedi et al., 2013). Customer knowledge management is relatively a new subject and there are few studies in service organizations about this concept. The present study wants to check the effective factors on customer knowledge management development in Bandar Abbas Rajaei customs. Therefore, the goal of this

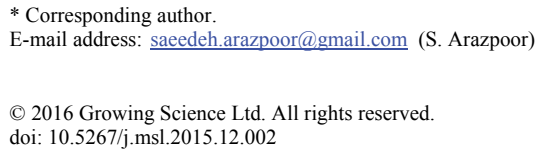


research is to verify effective factors on customer knowledge development such that by using them any organization can step toward customer knowledge management development.

\section{Expressing issue and the subject's importance}

To accomplish the missions and achieving their goals, organizations have numerous resources and properties. Some of them are really valuable and functional that have crucial role for gaining competitive advantage. Management experts consider knowledge as a final replacement for production, monetary wealth and property (Toffler 1990).

Although knowledge is considered as a competitive key factor in world economy, for successful presence in these days' dynamic market, another important factor must be considered named customer. Customer knowledge management provides the possibility to recognize appeared opportunities in market with higher possibility and increase competitive advantage. Customer knowledge management is associated with acquiring, sharing and disseminating knowledge of customers for benefiting both customers and organizations (Mousakhani et al., 2012). Customer knowledge is an important concept for many organizations and it fills the gap between what we think and what the customer really wants. Customer knowledge management also can be called as using the knowledge gained from customer, about customer and collected for customer that is accomplished for services' improvement. Managing customer knowledge is dynamic processes that is executed in order to improve valuable customer information to improve the relationship with its customer.

There are different definitions of knowledge management that consider knowledge management as a process that help organizations in identifying, selecting, organizing, publishing, distributing and transferring the information (Turban et al., 2008). Customer knowledge management is acquisition, sharing and promoting knowledge in customer's mind in favor of organization (Gibbert et al., 2002). Customer knowledge management is defined in association with acquisition, sharing and development of customer knowledge and the objective of common interest between customers and organizations (Davenport et al., 2001). Salavati et al. (2010) investigated the effects of knowledge management, customer relationship management in banking industry and reported that knowledge management was the most important factor influencing on customer satisfaction followed by loyalty, attraction and interaction. Hosseinzadeh et al. (2012) measured the level of knowledge management in medical school and reported that the rate of knowledge management components was within desirable level. Attafar et al. (2013) investigated the role of customer knowledge management in improving organizationcustomer relationship. They reported that inadequate budgets, lack of commitment of high managers in customers' knowledge management and weak relationship of designing barriers and customers' knowledge management performance were the most important barriers for development of firms. Larson and Susanna (2004) presented a survey on managing customer loyalty in the automobile industry and reported that organization culture had a positive correlation with knowledge management. Pastor (2011) performed a survey on organizational culture factors that can influence knowledge transfer and reported that there was a relationship between organization culture and effective factors on knowledge transfer.

The primary purpose of this paper is associated with customer knowledge within customs' organization. In this research, we try to explain the effective factors on customer knowledge development in custom organization located in south part of Iran. The researcher seeks to find out whether or not organizational culture factors, training, strategy, information infrastructure, organizational infrastructure, leadership and management commitment, organizational conflict, standardization, inefficient business processes, communication, complementary skills, support budget are effective on developing organizational knowledge management. 


\section{Conceptual model of research}

Conceptual model of research is designed based on previous studies on this field (Attafar et al., 2013) and the interviews with experts and the managers of customs area have been executed and the effective factors on customer knowledge management development were recognized and the conceptual research model was formed. Fig. 1 shows the proposed study of this paper.

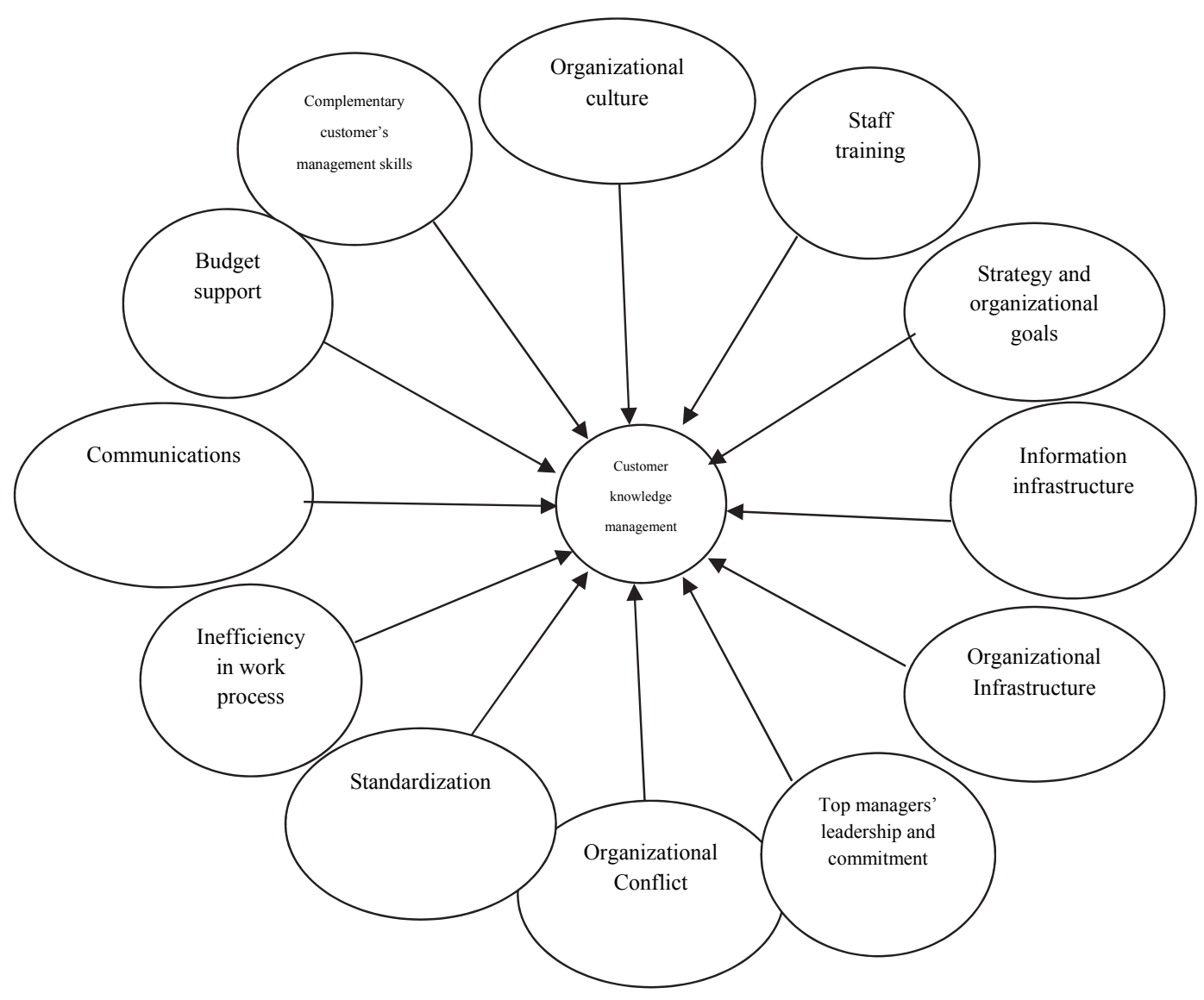

Fig. 1. The conceptual research model (Attafar et al., 2013)

This research, in terms of goal, is functional and, in terms of essence and method, is also a kind of descriptive study. The population of this research included all 440 staff and managers from different levels of Bandar Abbas Rajaei customs. Therefore, the sample size is calculated as follows,

$$
n=\frac{N \times z_{\alpha / 2}^{2} \times p \times q}{\varepsilon^{2} \times(N-1)+z_{\alpha / 2}^{2} \times p \times q},
$$

where $N$ is the population size, $p=1-q$ represents the yes/no categories, $z_{\alpha / 2}$ is CDF of normal distribution and finally $\varepsilon$ is the error term. Since we have $p=0.5, z_{\alpha / 2}=1.96$ and $N=440$, the number of sample size is calculated as $n=205$.

Collecting data method in different levels of this research is as follows:

A) Library studies: In order to develop theoretical principles of research, Internet and library studies were used. 
B) Questionnaire: for assessing research hypothesis and the relationship between variables, we have used questionnaire tools for collecting data.

Cronbach alpha was well above the desirable level and Kolmogorov-Smirnov has indicated that the data were normally distributed. Therefore, for analyzing data one-sample t-test is used.

\section{The results}

In this section, we present the results of the implementation of t-student as well as Freidman tests to examine the hypotheses of the survey. Table 1 shows the results of $t$-student test.

Table 1

The results of the implementation of t-student test

\begin{tabular}{lccccc}
\hline Variable & Number & Average & t & df & Sig. \\
\hline Culture & 205 & 3.83 & 17.28 & 204 & .00 \\
Staff training & 205 & 3.80 & 16.67 & 204 & .00 \\
Strategy and goals & 205 & 3.85 & 19.79 & 204 & .00 \\
Information infrastructure & 205 & 3.66 & 12.42 & 204 & .00 \\
Organizational Infrastructure & 205 & 3.84 & 19.04 & 204 & .00 \\
Leadership and management commitment & 205 & 3.60 & 10.99 & 204 & .00 \\
Organizational Conflict & 205 & 3.76 & 17.95 & 204 & .00 \\
Standardization & 205 & 3.93 & 13.85 & 204 & .00 \\
Inefficiencies in the process & 205 & 3.94 & 15.09 & 204 & .00 \\
Communications & 205 & 3.81 & 13.95 & 204 & .00 \\
Budget support & 205 & 3.80 & 12.51 & 204 & .00 \\
Management skills & 205 & 3.90 & 15.94 & 204 & .00 \\
\hline
\end{tabular}

The results of one sample t-test for all variables show that the value of $t$ is more than standard value of 1.96 and also significant level is less than 0.05 so all the null hypotheses are rejected. The results of Freidman test in variables ranking show that the most grade mean belongs to training with the value of 5.47 and the least grade mean belongs to leadership variable with the mean of 3.31. The Friedman test components show that Chi square with 11 degrees of freedom in the amount of 27.86 is meaningful when the level of significance is 0.05 .

\section{4- General conclusion and suggestions}

\subsection{The first hypothesis}

Considering the confirmation of this hypothesis, culture is a subject that is presented in knowledge management in organizational behavior authority. Following new ideas and researches in management, organizational culture has got growing importance and forms one of focal and main discussion of management. So according to this hypothesis we recommend the custom organization

1) to make necessary changes to reach a compatible culture with new requirements,

2) The custom's managers must provide relatively the facilities of staff knowledge promotion in terms of organizational culture.

\subsection{The second hypothesis}

According to the results of testing the second hypothesis, achieving organization goals depends on employees' abilities in accomplishing responsibilities and adapting to the environment. So for developing and promoting educational goals it is necessary to achieve high quality skills.

\subsection{The third hypothesis}

Goal setting needs innovations and creativity and keeping that needs commitment to that target so using these tools in customers' organizational management development is recommended: 
1) A strategy description for Rajaei customs; it must be correct, brief, organized and without ambiguity.

2) Customs organization's policy determines the issues that is just for that customs and understand what the customers' expectations and wishes and also beneficiary for them.

\subsection{The fourth hypothesis}

The process of globalization is integrated with the widespread communication, human and information technology and this increases the best utilization of physical equipment. Therefore, management of custom organization must take advantage of recent development of facility locations and optimal usage of resources. The management team also need to have the access to some facilities for necessary communications.

\subsection{The fifth hypothesis}

According to the results of testing the fifth hypothesis, infrastructures play essential role for development of knowledge management. Therefore, the organization must invest in necessary equipment to have sustainable development on information technology. They also need to implement knowledge management in different areas such as culture and advertising, skills training, providing facilities and tools for knowledge management, the field of technology and information management.

\subsection{The sixth hypothesis}

Achieving a cultivated, free and developed country needs targeted, up-to-date and principled work of conscientious and committed manpower. Therefore, management teams have to increase the level of self-confidence among regular employees and increase the level of commitment.

\subsection{The seventh hypothesis}

Conflict is a phenomenon that has positive and negative effects on people and organizations' performances. Using conflict effectively and correctly cause improvement and improve organization's health and it could improve knowledge management in Rajaei customs.

\subsection{The eighth hypothesis}

According to the results of the eight hypothesis, the organization needs to reach some good standards for their rules and regulations. This helps improve the quality of services and provides better customer satisfaction.

\subsection{The ninth hypothesis}

There is no doubt that business models are faced with rapid changes in today's economy. Therefore, management team must be able to make necessary changes by improving new processes and improving the existing ones.

\subsection{The tenth hypothesis}

One of the thinkable items in knowledge management, due to the dynamic nature is its relationship with the communication. In our survey, a good flow of communication must be created within the organization so that customer could take advantage of it.

\subsection{The eleventh hypothesis}

Using new methods of budgeting along with prevention of slow workflow within organization is considered as very effective way in promoting social and economic purposes. Therefore, quantitative 
and measurable targets must be considered to achieve the implementation of organization knowledge management.

\subsection{The twelfth hypothesis}

To establish the specialized knowledge management within the organization, different skills are required. Therefore, expert knowledge or professional knowledge management of customs must be identified.

Finally, the results of this survey are consistent with other findings reported in the literature (Hosseinzadeh et al., 2012; Tarzi \& Bolourian Tehrani, 2011; Mousakhani et al., 2012).

\section{Acknowledgement}

The authors would like to thank the anonymous referees for constructive comments on earlier version of this paper.

\section{References}

Abedi, E., Divan dari, A., Mahmoudian, M., \& Shami Zanjani, M. (2013), Formulation of the customer knowledge management in private commercial banks of Iran. Business Administration, 6(1), 41-66.

Attafar, A., Sadidi, M., Attafar, H., \& Shahin, A. (2013). The role of customer knowledge management (CKM) in improving organization-customer relationship. Middle-East Journal of Scientific Research, 13(6), 829835.

Davenport, T. H., Harris, J. G., \& Kohli, A. K. (2001). How do they know their customers so well?. MIT Sloan Management Review, 42(2), 63.

Gibbert, M., Leibold, M., \& Probst, G. (2002). Five styles of customer knowledge management, and how smart companies use them to create value.European Management Journal, 20(5), 459-469.

Haji Karimi, A., \& Mansourian, T. (2012). Examine and clarify the role of customer knowledge management in improving organizational performance. Journal of Business Management excavations, 4(8).

Hosseinzadeh, A., Sh'bani, A., \& Siadat, S. A. (2012). The application of knowledge management among hospital staff and academic libraries Covered Tabriz University of Medical Sciences Based on Hissig. Health Information Management Journal, 24.

Larson, S., \& Susanna, H. (2004). Managing customer loyalty in the automobile industry. Department of business administration and social sciences.

Mousakhani, M., Haghighi, M., \& Torkzadeh, S. (2012), Offering a model to gain customer loyalty by using customer knowledge management in the banking industry Country (Private banks). Business Management Journal, 4(2).

Turban, E., Leidner, D., McLean, E., \& Wetherbe, J. (2008). Information Technology for management. John Wiley \& Sons.

Pastor, I. (2011). Organizational culture factors that can influence knowledge transfer. EIRP Proceedings, 6.

Salavati, A., Kafcheh, P., \& Salehpour, K. (2011). Effects of Knowledge Management on Customer Relationship Management in Refah Bank checking, (Case Study: Kurdistan Province). Beyond Management, 4(16).

Tarzi, N., \& Bolourian Tehrani, M. (2011). Key Success Factors on Customer Relationship Management in Insurance Companies (Case Study:Saman insurance). Marketing Management Journal, 7.

Toffler, A. (1990). Power shift: Knowledge, wealth, and violence at the edge of the twenty-first century. New York \& London: Bantam Books.

Toriani, S., \& Angeloni, M. T. (2011). CRM as a support for knowledge management and customer. JISTEMJournal of Information Systems and Technology Management, 8(1), 87-108.

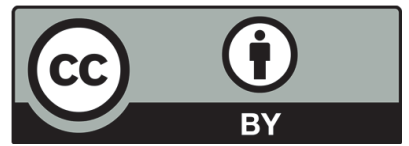

(C) 2016 by the authors; licensee Growing Science, Canada. This is an open access article distributed under the terms and conditions of the Creative Commons Attribution (CC-BY) license (http://creativecommons.org/licenses/by/4.0/). 